\title{
Análise do sistema de logística reversa de lâmpada fluorescente na cidade de São Paulo
}

Analysis of the reverse logistic system of fluorescent lamp of the São Paulo city

Análisis del sistema de logística inversa de lámpara fluorescente en la ciudad de São

Paulo

\author{
Samara Nicolau Puopolo \\ Mestranda em habitação, IPT, Brasil \\ Samara.puopolo@gmail.com \\ Cláudia Echevenguá Teixeira \\ Professora Doutora, IPT, Brasil \\ cteixeira@ipt.br
}

Ana Candida Melo Cavani Monteiro

Pesquisadora, IPT, Brasil anacandi@ipt.br 


\section{RESUMO}

Com a vida moderna e o consumismo desenfreado nas cidades observa-se o aumento dos resíduos sólidos gerados, que são descartados, na maioria das vezes, indevidamente. Dentre tantos resíduos encontrados nas edificações, destacam-se as tecnologias de iluminação que têm sido muito difundidas no mercado. Em contrapartida, a questão do descarte não. Nesse contexto, o presente artigo tem como foco o resíduo de lâmpada fluorescente (LF), que de acordo com a ABNT 10.004 é classificado como resíduo de classe I, devido a sua alta periculosidade, com substâncias tóxicas e cancerígenas em sua composição, como o mercúrio por exemplo. Com a anuência da Política Nacional de Resíduos Sólidos, a PNRS 12.305/2010, foi elaborado o acordo setorial de lâmpadas mercuriais, e para que ocorra o recolhimento dos resíduos sólidos perigosos de LF, por meio da responsabilidade compartilhada e da logística reversa foi criada uma gestora nacional. Assim, ressalta-se a importância da responsabilidade compartilhada entre todas as partes interessadas no ciclo de vida deste produto. Objetiva-se avaliar o grau de conhecimento da população para divulgação e apresentação dos locais de coleta deste resíduo perigoso. Identificou-se os agentes envolvidos na logística reversa, por meio de observações, entrevistas, análises de hábitos, costumes e necessidades dos consumidores, informações sobre os serviços de coleta de distribuidores, importadores, fabricantes e as associações envolvidas. Busca-se, desta maneira, evidenciar a necessidade de uma conscientização e de ações para prolongar o ciclo de vida desses produtos, a fim de prevenção de contaminações no meio ambiente e melhorias na saúde dos seres vivos.

PALAVRAS-CHAVE: Resíduo sólido. Lâmpada fluorescente. Logística reversa.

\section{ABSTRACT}

With modern life and the rampant consumerism in the cities it is observed the increase of solid residue generated, that are disposed of, most of the time, unduly. Among many residues found in buildings, lighting technologies that have been widely used in the market, in contraste, the issue of disposal does not. In this context, the present article focuses on the residue of fluorescent lamp, that according to the Brazilian Association of technical standards ABNT 10,004 , this residue is classified as class I, due to its high dangerousness, with carcinogenic and toxic substances in your composition, as the Mercury for example. With the consent of the Brazilian solid Residues Policy, the PNRS 12,305/2010, the industry agreement of mercury lamps, and for the collection of solid residue hazardous LF, through shared responsibility and logistics It created a national Manager reverse. Thus, the importance of shared responsibility among all stakeholders in the life cycle of this product. The objective is to assess the degree of knowledge of the population for the dissemination and presentation of the places of collection of this hazardous residue. Was identified the actors involved in reverse logistics, through observations, interviews, analyses of habits, customs and needs of the consumers, information about the collection services of distributors, importers, manufacturers and the associations involved. Search this way, evidencing the need of a awareness and actions to prolong the life cycle of these products, in order to prevent contamination in the environment and improvements in the health of living beings

KEY-WORDS: Solid Residue. Fluorescent lamps. Reverse logistics.

\section{RESUMEN}

Con la vida moderna y el consumismo desenfrenado en las ciudades se observa el aumento de los residuos sólidos generados, que son descartados, la mayoria de las veces, indebidamente. Entre tantos residuos encontrados en los edificios, las tecnologías de iluminación que han estado muy difundidas en el mercado. En contraste, el cuestion del descarte no. En este contexto, el presente artículo tiene como foco el residuo de lámpara fluorescente (LF), y de acuerdo con la ABNT 10.004 se clasifica como residuo de clase I, debido a su alta peligrosidad, con sustancias tóxicas y cancerígenas en su composición, como el mercurio por ejemplo. Con el consentimiento de la Política Nacional de Residuos Sólidos, PNRS 12.305/2010, se elaboró el acuerdo sectorial de lámparas mercuriales, y para el recuerdo de los peligrosos residuos sólidos de LF, a través de la responsabilidad compartida y la logística se creó uma gestora nacional. Así, se ressalta la importancia de la responsabilidad compartida entre todas las partes interesadas en el ciclo de vida de este producto. Es objetivo evaluar el grado de conocimiento de la población para divulgación y presentación de los locales de recolección de este residuo peligroso. Se identificaron los agentes involucrados en la logística inversa, por medio de observaciones, entrevistas, análisis de hábitos, costumbres y necesidades de los consumidores, información sobre los servicios de recolección de distribuidores, Importadores, fabricantes y el Asociaciones involucradas. De esta manera, buscamos destacar la necesidad de una conciencia y acciones para prolongar el ciclo de vida de estos productos con el fin de prevenir la contaminación en el medio ambiente y la mejora de la salud de los seres vivos.

PALABRAS CLABE: Residuo solido. Lámpara fluorescente. Logística inversa. 


\section{INTRODUÇÃO}

As edificações em diferentes fases do seu ciclo - construção, uso e demolição - são fontes de resíduos gasosos, líquidos ou sólidos, perigosos ou não. Na fase de construção são gerados entulhos, restos de madeiras, de instalações elétricas e sanitárias, de tintas, de solventes, entre outros materiais (KARPINSK, 2009). Alguns destes materiais são classificados como materiais perigosos e não perigosos pela Norma Brasileira NBR 10.004 (ABNT, 2004).

$\mathrm{Na}$ fase de uso da edificação para fins residenciais são produzidos resíduos gasosos, resíduos líquidos e resíduos sólidos. Os resíduos sólidos, classificados como não perigosos são: papel, plástico, metal, material orgânico, vidros (material cortante); são classificados como perigosos: medicamentos vencidos, pilhas, baterias, lâmpadas fluorescentes, eletrônicos, entre outros (BRASIL, 2010c). É fundamental o manejo, o processamento e a destinação final adequada dos resíduos gerados nas edificações, pois o descarte inadequado pode causar, direta ou indiretamente, os inconvenientes como: enchentes, poluição da água, do ar e do solo, poluição visual e olfativa (JACOBI, P. R.; BESEN, G. R, 2011).

A consolidação das indústrias focada na produção e consumo de grandes proporções ao longo dos últimos anos, tem proporcionado um volume de produtos superior ao necessário, e consequentemente a geração descontrolada de resíduos sólidos (DEMAJOROVIC, LIMA, 2013). Segundo a Abrelpe (2016), houve uma ligeira queda na geração de resíduos sólidos na região sudeste do país em 2015 e 2016, que foram respectivamente de $1.252 \mathrm{~kg} / \mathrm{hab}$./dia e 1.213 $\mathrm{kg} / \mathrm{hab}$./dia.

Observa-se que dentre os resíduos sólidos classificados como perigosos, atualmente há aqueles que são jogados comumente com os demais resíduos, e isso ocorre por conta da falta de informação aos consumidores. Dentre tantos resíduos sólidos perigosos lançados indevidamente pelos edifícios, destacam-se as novas tecnologias de iluminação. Essas tecnologias são consideradas importantes para o sistema de iluminação nos edifícios, e permite aos usuários a qualidade de iluminação, principalmente nas atividades noturnas. Com a crise energética de 2001, que impulsionou o banimento das lâmpadas incandescentes, através da Portaria Interministerial $n^{\circ} 1.007$, houve um considerável aumento de utilização de lâmpadas fluorescentes e mais recentemente de Light Emitting Diode (LED) (BRASIL, 2010a).

A estimativa de consumo de lâmpadas fluorescentes no país ainda é grande, sendo que, em 2014, houve um consumo de 350 milhões de lâmpadas fluorescentes, entre as compactas e tubulares (MISSIAGGIA, 2015). Assim, o presente artigo, têm como objetivo analisar a importância da divulgação de informações relacionadas a essa pesquisa e apresentar os locais de coleta do resíduo perigoso de lâmpadas fluorescentes, que são utilizadas em grande escala nas edificações em geral, pelo seu custo associado com a necessidade do consumidor final.

$\mathrm{Na}$ aquisição de produtos de iluminação, segundo o Procel Info (2006), são relevantes ao consumidor final e ao comércio (distribuidores) questões de eficiência energética e de economia. Em contrapartida, nunca houve uma preocupação ou qualquer atenção quanto à 
questão do descarte. Os consumidores deste produto perigoso deveriam obter no momento da compra, informações sobre a periculosidade do produto após seu uso, mas isso não ocorre. O descarte dos resíduos perigosos é preocupante, devido a sua composição química que é de alta periculosidade (APLIQUIM BRASIL RECICLE, 2010). De acordo com a NBR 10.004, o resíduo de LF, é classificado como resíduo perigoso classe I (ABNT, 2004). Segundo Junior e Windmöller (2008), a Tramppo (2017) e Apliquim Brasil Recicle (2010), a taxa de reciclagem é ínfima de lâmpadas fluorescentes que receberam o descarte adequado, considerando-se todas as lâmpadas consumidas.

Com a anuência da Política Nacional de Resíduos Sólidos, a PNRS 12.305/2010, foi elaborado o acordo setorial de lâmpadas mercuriais, nos quais propõe a destinação final adequada a esses resíduos por meio da logística reversa (LR) e da responsabilidade compartilhada, porém observa-se que a falta de informações e de políticas adequadas ainda não cumprem este programa. Desta forma, questiona-se como tem sido destinado esse resíduo e quais são os pontos de coleta na cidade de São Paulo, para que haja o descarte adequado para posterior tratamento e descontaminação do resíduo tratado.

\section{RESÍDUOS SÓLIDOS}

Os resíduos sólidos se originam de produtos pós-consumidos, que são gerados normalmente nas edificações residenciais, comércios e industrias. Os resíduos sólidos são compostos, por matéria orgânica, como por exemplo: restos de comida, papel higiênico, fraldas, entre outros; e outros materiais inorgânicos como: plástico, metal, papel e vidro. Além desses resíduos sólidos, há também os considerados resíduos perigosos, dentre eles: pilhas, baterias, eletroeletrônicos, tintas e solventes, medicamentos e lâmpadas fluorescentes. Sendo este último resíduo, o objeto de estudo do presente artigo e serão analisadas a seguir.

\subsection{Evolução das tecnologias de iluminação}

A iluminação artificial foi desenvolvida por Thomas Edson, em 1879, a qual ficou conhecida como lâmpada incandescente. Em busca da eficiência energética, houve o avanço da tecnologia de iluminação, e em meados da década de 1930, surgiram as lâmpadas fluorescentes, conhecidas também como lâmpadas de descarga de baixa pressão. Desde o surgimento das lâmpadas fluorescentes, o fornecimento desses produtos para o consumidor passou por variados formatos e tamanhos. Inicialmente eram encontradas somente no formato tubular e atualmente são encontradas em tamanhos menores para atender a necessidade dos consumidores, principalmente devido a substituição das lâmpadas incandescentes do mercado brasileiro (POLANCO, 2007). A última tecnologia de iluminação artificial que entrou no mercado, foi a tecnologia Light Emitting Diode (LED), sendo esta a com maior eficiência energética dentre as tecnologias já disponíveis (SÃO PAULO, 2014a). 


\subsection{Lâmpada fluorescente}

As lâmpadas fluorescentes são constituídas de um vidro muito fino, recoberto internamente de pó de fósforo que adicionados alguns compostos, formam os chamados fósforos vermelhos, verde e azul. O tubo de vidro é preenchido por gás inerte (argônio, neônio, criptônio e/ou xenônio) a baixa pressão e o vapor de mercúrio a baixa pressão parcial. Devido a isso, é conhecida também como uma lâmpada de descarga de baixa pressão. Esse vapor gera radiação ultravioleta, que absorvida pelo pó fluorescente do revestimento interno do vidro fino, gera a fluorescência, transformando em luz visível (ANDRÉ, 2004).

Segundo a Environment Protection Agency (1994), a composição do pó fosfórico de uma lâmpada fluorescente, é composto por vários elementos químicos, sendo eles: o alumínio $(3.000 \mathrm{mg} / \mathrm{kg})$, o antimônio $(2.300 \mathrm{mg} / \mathrm{kg})$, o bário $(610 \mathrm{mg} / \mathrm{kg})$, o cádmio $(1.000 \mathrm{mg} / \mathrm{kg})$, o cálcio $(170.000 \mathrm{mg} / \mathrm{kg})$, chumbo $(75 \mathrm{mg} / \mathrm{kg})$, cobre $(70 \mathrm{mg} / \mathrm{kg})$, ferro $1.900(\mathrm{mg} / \mathrm{kg})$, magnésio (1.000 mg/kg), manganês $4.400(\mathrm{mg} / \mathrm{kg})$, mercúrio $(4.700 \mathrm{mg} / \mathrm{kg})$, níquel $(130 \mathrm{mg} / \mathrm{kg})$, sódio $(1.700 \mathrm{mg} / \mathrm{kg})$ e zinco $(48 \mathrm{mg} / \mathrm{kg})$.

Esses elementos químicos têm função vital para o bom funcionamento das lâmpadas fluorescentes. E desses elementos químicos encontrados nas lâmpadas fluorescentes, os seus efeitos nos seres vivos podem causar muitos inconvenientes, por exemplo o mercúrio pode causar. bioacumulação, lesões no córtex, alterações nos orgãos do sistema cardiovascular e endócrino. sintomas: paralisia, dormência nos lábios, mãos e pés, distúrbios emocionais, fadiga, perda de memória, cefaleia, gengivite, estomatite e gosto metálico. Além disso, pode causar problemas no estomago, distúrbios renais, distúrbios gastrointestinais, sistema respiratório, sistema neurológicos, distúrbios visuais, perda de audição, tremores muscular, paralisia cerebral, má formação fetal, alterações genéticas, no metabolismo e até a morte (SÃO PAULO, 2014a; WIENS, 2001; UNEP, 2013). Em relação ao chumbo, outro metal danoso, pode causar problemas carcinogênico e teratogênico, irritabilidade, tremores musculares, lentidão de raciocínio, distúrbios neurológicos, problemas gastrointestinais e renais, dores de cabeça, convulsões, alucinação, insônia e hiperatividade. em altas concentrações pode levar até a morte (SÃO PAULO, 2014a).

Diante dessas informações, apresentadas anteriormente, urge a necessidade de pesquisas sobre o descarte adequado deste produto pós-consumo e os locais específicos de coleta para atender os consumidores em atendimento a PNRS.

\subsection{Descarte de lâmpada fluorescente}

Segundo a ABNT 10.004, as lâmpadas fluorescentes são classificadas como resíduo sólido perigoso, na classe I, com código de identificação $\mathrm{F}-044$, devido a sua alta periculosidade (ABNT, 2004). Para Durão Junior e Windmöller (2008), Apliquim Brasil Recicle (2010) e 
Tramppo (2016), somente $6 \%$ do estoque de lâmpadas queimadas do país recebeu o tratamento de descontaminação. Além disso, os custos com a descontaminação dos resíduos das lâmpadas fluorescentes ainda são altos.

A nível municipal, há a Lei Municipal $n^{\circ} 12.653 / 98$, que fixa normas que estabelecem de forma correta sobre o descarte de lâmpadas fluorescentes. No art. 10: "Fica proibido o descarte como lixo comum de lâmpadas fluorescentes" (SÃO PAULO,1998). No Plano de Gestão Integrada de Resíduos Sólidos da cidade de São Paulo (PGIRS), expõe a responsabilidade compartilhada pelo órgão público perante aos resíduos dos produtos que devem atender a logística reversa, dentre eles o resíduo de lâmpada fluorescente (SÃO PAULO, 2014b).

Na esfera estadual, o art. 2 da Resolução SMA n ${ }^{\circ} 45$, obriga os fabricantes, importadores, distribuidores e comerciantes, dos produtos que exijam sistemas especiais para 0 acondicionamento, armazenamento, coleta, transporte, tratamento ou destinação final evitando danos ao meio ambiente e à saúde pública. Mas ainda nada foi elaborado e assinado relacionado ao resíduo de lâmpada fluorescente no estado de São Paulo.

A Política Nacional de Resíduos Sólidos (PNRS), a Lei Federal $n^{\circ} 12.305$ de 2010, que visa minimizar os impactos ambientais, por meio de metas para a eliminação e a recuperação dos lixões, da inclusão social e da emancipação econômica de catadores de materiais reutilizáveis e recicláveis. Além disso, para os materiais perigosos essa lei utiliza instrumentos como: a logística reversa e responsabilidade compartilhada (BRASIL, 2010c). Após a anuência da referida lei e do Decreto 7.404, que regulamentou a PNRS é que impulsionou nos últimos anos, a realização do acordo setorial de lâmpadas mercuriais e que está sendo possível colocar em prática o sistema de logística reversa de LF no país (BRASIL, 2010b).

Após isso, é que foi dado maior importância na logística reversa, criando o Comitê Orientador para a implantação da logística reversa de lâmpadas mercuriais, incluindo nestes produtos as lâmpadas fluorescentes (SINIR, 2017).

\section{RESPONSABILIDADE COMPARTILHADA E LOGÍSTICA REVERSA.}

Segundo a PNRS, a responsabilidade compartilhada e a logística reversa, são instrumentos importantes que têm por objetivo contribuir no desenvolvimento sustentável, na qual propõe a destinação final adequada dos resíduos sólidos.

Desta maneira, a responsabilidade compartilhada impõe que todos os envolvidos na cadeia do produto tenham a sua parcela de responsabilidade na utilização do produto, sendo assim, todos os envolvidos são responsáveis pelo descarte. Já a logística reversa é o retorno do produto pós-consumo voltando como resíduo para os distribuidores, fabricantes e importadores que são obrigados por lei a coletá-las do consumidor e dar a destinação final adequada. No caso de lâmpadas fluorescentes, todos os envolvidos são responsáveis pelo tratamento e descontaminação do produto e a coleta de LF e é paga pelo ecovalor (MMA, 
2017).

Assim, esses dois instrumentos são relevantes e ao serem colocados em prática contribuem no descarte final adequado, não permitindo que as lâmpadas fluorescentes tenham o destino inadequado como o lixo convencional ou, que sejam encaminhadas para os materiais reciclados, desviando assim, esses resíduos dos aterros e cooperativas, e aumentando o ciclo de vida dos materiais, evitando contaminações e poupando recursos naturais.

Como estudo de caso, foi analisada a logística reversa das lâmpadas fluorescentes na cidade de São Paulo a partir da metodologia descrita a seguir.

\section{METODOLOGIA}

O presente trabalho se trata de uma pesquisa qualitativa, com base no tipo exploratória e descritiva, com ação investigativa, que foi baseada em observação e obtenção dos dados de informações sobre a logística reversa de lâmpadas fluorescentes na cidade de São Paulo. A pesquisa foi realizada com o auxílio de bibliografia especializada e na rede mundial de sites nacionais e internacionais, sobre a situação da logística reversa de lâmpadas fluorescentes, por meio de revisão bibliográfica, visitas em homepages, pesquisa de campo, entrevistas com fabricantes/importadores, fornecedores/distribuidores, associações pertinentes ao tema desta pesquisa, consumidores e gestores pós-uso das lâmpadas fluorescentes e visitas técnicas.

A pesquisa qualitativa, que segundo Moresi (2003), é aquela que determina o que é importante e porque, incluindo a importância de trabalhar com uma amostra heterogênea de pessoas durante a pesquisa. Dessa maneira, foram adotadas amostras heterogêneas de consumidores, sendo escolhidos os com maiores níveis de instruções. As informações foram coletadas no período de janeiro de 2016 ao mês de janeiro de 2018, acompanhando assim a fase piloto de implantação do sistema de logística reversa de lâmpadas fluorescentes na cidade de São Paulo e no país. Os resultados apresentados são qualitativos, dos quais são bases para as análises, discussões e conclusões.

\section{ESTUDO DE CASO: A CIDADE DE SÃO PAULO}

Na cidade de São Paulo, antes do acordo setorial, em meados de 2012, já havia nesta cidade a iniciativa de algumas empresas do setor privado que contribuía no descarte de LF doméstica na cidade de São Paulo (ROCHA, 2016; SÃO PAULO, 2014b ). Mas foi devido ao acordo setorial, que têm sido instaladas nas maiores cidades do Brasil, os pontos de coletada de lâmpadas fluorescentes. A cidade de São Paulo foi a primeira cidade contemplada por esse benefício e foi a primeira cidade da lista, por ser a cidade mais populosa do Brasil. Os primeiros estados que têm sido contemplados com a coleta deste material foram: São Paulo, Rio de Janeiro, 


\section{Revista Nacional de}

Paraná, Rio grande do Sul e Minas Gerais (SINIR, 2017).

Conforme São Paulo (2014b, p.33), prevê que a prefeitura contribuiria no recolhimento deste resíduo. Porém na prática, não há o recolhimento do resíduo de lâmpada fluorescente em pontos específicos da cidade, como consta no PGIRS.

Estimulado pela PNRS, o acordo setorial de resíduo de LF obrigou os envolvidos deste setor a se organizarem para a implantação do sistema de logística reversa de LF no país.

\section{1. RESULTADOS E DISCUSSÕES}

Como falado anteriormente, já havia antes do acordo setorial pontos de coleta do resíduo perigoso de LF em algumas redes de distribuidores. Mas os três primeiros pontos de coleta de LF instalados na cidade de São Paulo, pela gestora nacional Reciclus, foram apresentados no Quadro 1, iniciando assim, a implantação da logística reversa no país, de dezembro de 2016 a janeiro de 2017 (RECICLUS, 2016).

Quadro 1- Primeiros pontos de coleta do sistema de logística reversa na cidade de São Paulo implantado pelo programa nacional Reciclus

\begin{tabular}{|l|l|l|l|l|l|}
\hline \multicolumn{1}{|c|}{ ESTADO } & \multicolumn{1}{|c|}{ CIDADE } & \multicolumn{1}{c|}{ BAIRRO } & \multicolumn{1}{c|}{ LOJA } & \multicolumn{1}{c|}{ ENDEREÇO } & CEP \\
\hline S.P. & São Paulo & Butantã & Carrefour & $\begin{array}{l}\text { Avenida Professor Francisco } \\
\text { Morato, no 2.718 }\end{array}$ & $05512-300$ \\
\hline S.P. & São Paulo & Casa Verde & Andra & Avenida Casa Verde, no 3.031 & 02519-000 \\
\hline S.P. & São Paulo & Piqueri & Santil & $\begin{array}{l}\text { Av. Otaviano Alves de Lima, no } \\
6.800\end{array}$ & 02901-000 \\
\hline
\end{tabular}

Fonte: adaptado de Reciclus (2016)

Até o mês de janeiro de 2018, houve a ampliação do sistema de logística reversa chegando a cinquenta e cinco pontos de coleta de LF na cidade de São Paulo (RECICLUS, 2018), conforme apresentado na Figura 1. 


\section{Revista Nacional de}

Gerenciamento de Cidades

National Journal of Cities Mamagement

Figura 2 - Nível de instrução dos consumidores pesquisados (em números absolutos)

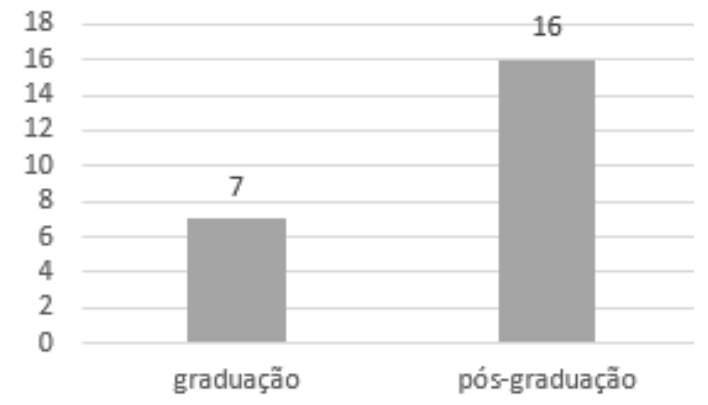

Fonte: Puopolo, Teixeira, Cavani (2018).

Da amostra total destes consumidores, verificou-se que 8 (oito) ou $34,8 \%$ deles não possuem nenhuma LF sendo utilizada em suas residências, 7 (sete) ou 30,4\% utilizam de cinco até dez LF, 6 (seis) ou 26,1\% dos consumidores utilizam mais de dez LF e somente 2 (dois) ou 8,7\% deles utilizam de uma a quatro LF, conforme apresentado a seguir na Figura 3.

Figura 3 - Consumidores de LF utilizadas nas residências dos consumidores pesquisados (em números absolutos)

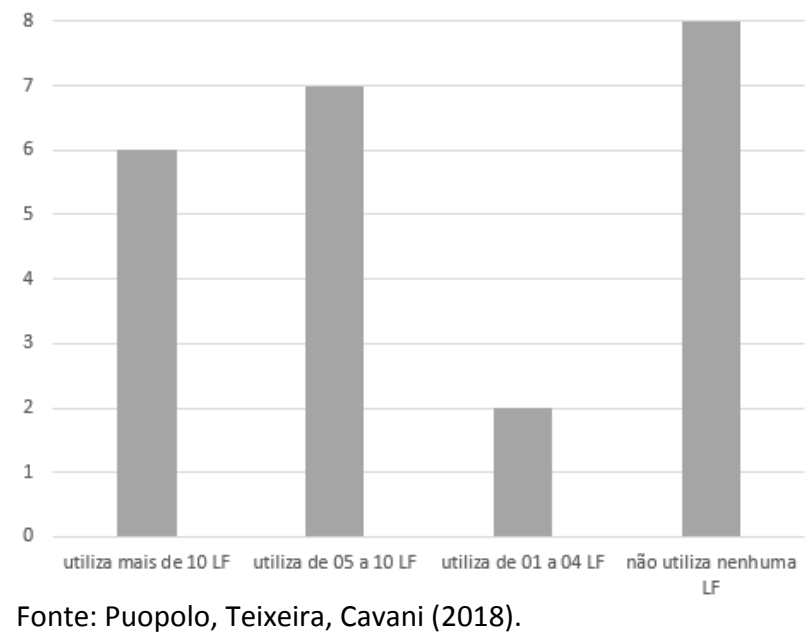

Quanto aos consumidores que descartam LF nas suas residências, 7 (sete) ou 30,4\% deles encaminham para a coleta de materiais recicláveis, 6 (seis) ou 26,1\% deles encaminham para o lixo convencional, 5 (cinco) ou $21,7 \%$ deles encaminham para a coleta especial, 4 (quatro) ou $17,4 \%$ dos consumidores não responderam, conforme apresentado na Figura 4. Sendo assim, pelo menos 13 (treze) ou 56,5\% dos 23 (vinte e três) consumidores pesquisados descartam o resíduo estudado em locais inapropriados. 


\section{Revista Nacional de}

Gerenciamento de Cidades

National Journal of Cities Mamagement

Figura 4 - Descarte de LF nas residências dos consumidores pesquisados (em números absolutos)

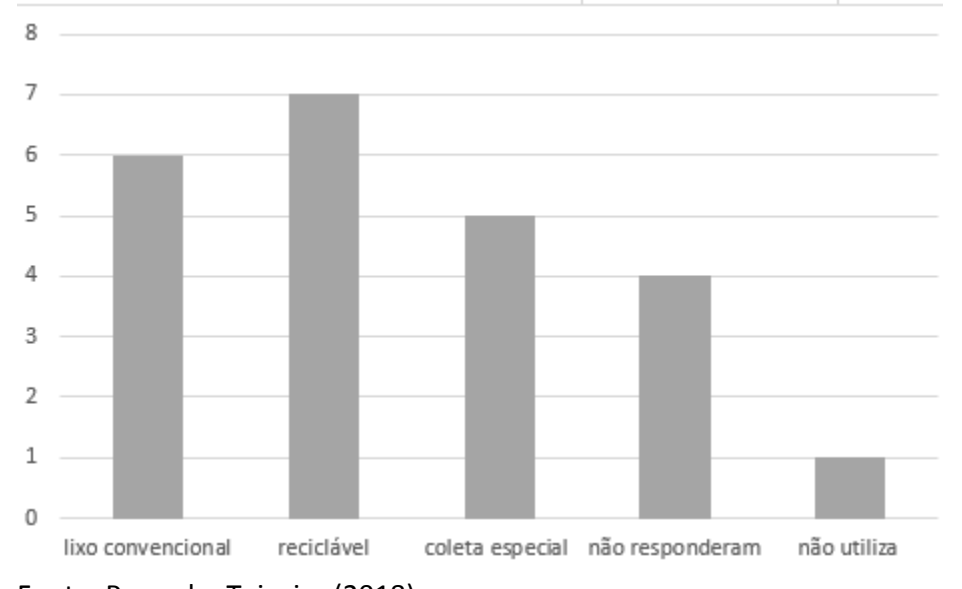

Fonte: Puopolo, Teixeira (2018).

Observou-se com esses resultados, que o resíduo de lâmpada fluorescente têm como destinos principais: o lixo convencional e as cooperativas de reciclagem de resíduos sólidos. Com a falta de informação sobre o descarte deste resíduo perigoso, esse é descartado erroneamente. Parte dos resíduos de LF são encaminhados diretamente, sem tratamento, para os aterros e para as cooperativas, contaminando outros materiais, agentes ambientais e o meio ambiente. Dos 23 (vinte e três) consumidores pesquisados, 14 (quatorze) deles que representam 60,9\% sabem dos riscos ambientais e de saúde que esse resíduo pode causar e os outros 9 (nove) consumidores, ou seja, 39,1\% deles não sabem, conforme apresentado na Figura 5.

Figura 5 - Consumidores pesquisados que sabem dos riscos ambientais e de saúde que a LF pode causar (em números absolutos).

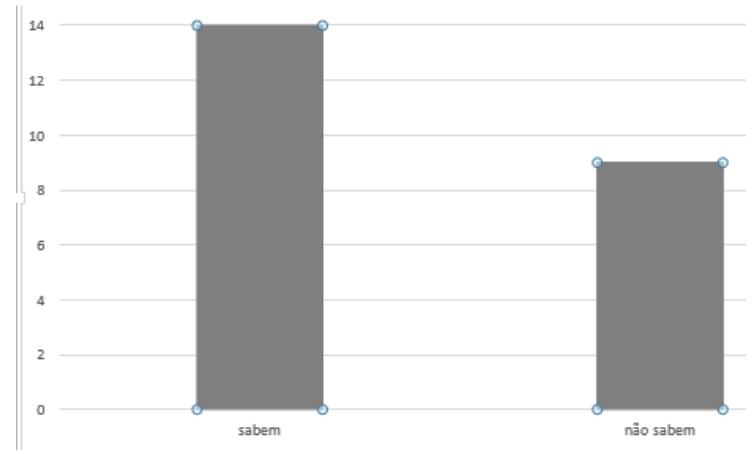

Fonte: Puopolo, Teixeira, Cavani (2018).

Além dos consumidores, também foram analisados 7 (sete) distribuidores de lâmpadas fluorescentes, sendo que 6 (seis) deles ou $85,7 \%$ coletam os resíduos de LF (dentre eles um coleta, quebra e encaminha para o lixo convencional), e 1 (um) não coleta o que representa $14,3 \%$, conforme apresentado no Quadro 2. 


\section{Revista Nacional de}

Quadro 2 - Descarte de lâmpadas fluorescente dos distribuidores pesquisados

\begin{tabular}{|l|l|l|l|}
\hline $\begin{array}{l}\text { REDE DE } \\
\text { DISTRIBUIÇÃo }\end{array}$ & COLETA LF & LOCAL DE DESCARTE & $\begin{array}{l}\text { DATA DAS ENTREVISTAS E } \\
\text { COLETA DAS } \\
\text { INFORMAÇÕES }\end{array}$ \\
\hline Leroy Merlin & $\operatorname{sim}$ & todas as lojas & $23 / 08 / 2016$ \\
\hline C\&C & $\operatorname{sim}$ & loja da Marginal Tietê & $23 / 08 / 2016$ \\
\hline Telha Norte & $\operatorname{sim}$ & consultar as lojas & $14 / 03 / 2016$ \\
\hline Carrefour & $\operatorname{sim}$ & consultar as lojas & $24 / 08 / 2016$ \\
\hline Conibase & $\operatorname{sim}$ & consultar as lojas & $05 / 10 / 2017$ \\
\hline Alba & $\operatorname{não}$ & não coleta & $13 / 09 / 2016$ \\
\hline Rede Construir & $\operatorname{sim}$ & $\begin{array}{l}\text { Após quebra do material é encaminhado } \\
\text { para o lixo convencional }\end{array}$ & $13 / 09 / 2016$ \\
\hline
\end{tabular}

Fonte: Puopolo, Teixeira (2018).

Observou-se que dos grandes distribuidores, todos já estão contribuindo com o sistema de logística reversa na cidade de São Paulo, mas em relação aos pequenos distribuidores não. Dos pequenos distribuidores, um deles não há coleta deste resíduo e o outro que coleta está com risco de contaminação no ambiente de trabalho, pois coleta, quebra o resíduo perigoso e encaminha o para o lixo convencional.

Na presente pesquisa, não foi identificado nenhum fabricante de LF em território brasileiro.

Em contrapartida, foram analisadas 5 (cinco) importadoras, dentre as quais todas as importadoras pesquisadas aderiram ao sistema de LR de LF por meio do acordo setorial, conforme apresentado no Quadro 3.

Quadro 3 - Descarte de lâmpadas fluorescente pelos importadores pesquisados

\begin{tabular}{|c|c|c|c|}
\hline IMPORTADORAS & $\begin{array}{l}\text { ATENDEM O } \\
\text { SISTEMA DE LR }\end{array}$ & COMO FOI EVIDENCIADO & $\begin{array}{l}\text { DATA DAS } \\
\text { ENTREVISTAS E COLETA } \\
\text { DAS INFORMAÇÕES }\end{array}$ \\
\hline Osram & Sim & $\begin{array}{l}\text { Contato telefônico, por e-mail e visita na } \\
\text { FEICON 2017; } \\
\text { Pertence ao acordo setorial; } \\
\text { Empresa é associada a Reciclus. }\end{array}$ & $\begin{array}{l}24 / 03 / 2016 \\
24 / 04 / 2018 \\
08 / 04 / 2017\end{array}$ \\
\hline Philips & Sim & $\begin{array}{l}\text { Contato telefônico, por e-mail e visita na } \\
\text { FEICON 2017; } \\
\text { Pertence ao acordo setorial; } \\
\text { Empresa é associada a Reciclus. }\end{array}$ & $\begin{array}{l}\text { 31/08/2016; } \\
\text { 08/04/2017. }\end{array}$ \\
\hline Golden & Sim & $\begin{array}{l}\text { Contato telefônico, por e-mail e visita na } \\
\text { FEICON 2017; } \\
\text { Pertence ao acordo setorial; } \\
\text { Empresa é associada a Reciclus. }\end{array}$ & $\begin{array}{l}25 / 08 / 2016 \\
08 / 04 / 2017\end{array}$ \\
\hline Ourolux & Sim & $\begin{array}{l}\text { Contato telefônico e visita na FEICON 2017; } \\
\text { Pertence ao acordo setorial; } \\
\text { Empresa é associada a Reciclus }\end{array}$ & $\begin{array}{l}\text { 08/04/2017; } \\
\text { 08/04/2017. }\end{array}$ \\
\hline Avant & Sim & $\begin{array}{l}\text { Contato telefônico e visita na FEICON 2017; } \\
\text { Pertence ao acordo setorial; } \\
\text { Empresa é associada a Reciclus }\end{array}$ & $\begin{array}{l}\text { 08/04/2017; } \\
\text { 08/04/2017. }\end{array}$ \\
\hline
\end{tabular}

Fonte: Puopolo, Teixeira, Cavani (2018). 
Assim, observou-se que as empresas importadoras pesquisadas aderiram ao acordo setorial, sendo elas associadas a gestora nacional Reciclus, o que possibilitou a criação do sistema nacional de logística reversa de lâmpadas fluorescentes.

O principal ponto que procurou-se investigar foi quais são as atitudes, programas e ações dos envolvidos na cadeia de LR de LF e com essa pesquisa foi possível notar que os programas e as ações relacionados ao tema avançaram no último ano e ampliou a rede de coletores de LF disponíveis na cidade de São Paulo e no país. Percebeu-se que a gestora nacional, Reciclus, está na fase de estruturação do sistema de logística reversa de LF, mas ainda falta conhecimento sobre o descarte do resíduo em questão para os consumidores como visto anteriormente.

\section{CONCLUSÃO}

É fato que o uso de LF gera economia de energia, mas após o seu uso ela vira resíduo que é classificado como perigoso, devido a sua composição conter vários metais pesados, dentre o mercúrio que é altamente tóxico. E quando misturados com os outros resíduos, principalmente os orgânicos, se tornam potencialmente mais tóxicos. O descarte inadequado de vários resíduos quando misturados, forma-se uma "bomba" para o meio ambiente e para os seres vivos, causando muitos tipos de doenças e em alguns casos até mesmo a morte. Diante disso, a sensibilização e pulverização de informações sobre o descarte de resíduos deve ser uma prática inevitável e urgente para mudar o cenário atual sobre os resíduos sólidos.

Houve a preocupação diante da aprovação da legislação nacional que cita o resíduo perigoso em questão, contudo na prática não há a responsabilidade compartilhado da esfera municipal, além disso, a fiscalização sobre o descarte deste resíduo é ineficiente e falta informações sobre os pontos de coleta para o consumidor final, que é o ator principal para a mudança deste cenário de toda a cadeia de logística reversa, ou seja, suas ações é a parte determinante desta cadeia.

Percebeu-se que embora mais da metade dos consumidores pesquisados saibam dos riscos ambientais que o descarte deste resíduo pode causar, mais da metade deles encaminham os resíduos para local inapropriado.

O descarte desses resíduos, têm sido inevitáveis devido ao grande consumo de LF na cidade, sendo que houve grandes avanços nos últimos anos em relação ao descarte do resíduo em questão, e que mais cautela e a pulverização dessas informações são relevantes na prevenção de contaminação do meio ambiente e aos seres vivos.

\section{Referências bibliográficas.}

ANDRÉ, A. S. Sistema eletrônico para lâmpadas de vapor de sódio de alta pressão. 2004. 134 f. Tese (Doutorado) Curso de Engenharia Elétrica, Universidade Federal de Santa Catarina, Florianópolis, 2004. 
APLIQUIM BRASIL RECICLE, 2010. Consulta geral a homepage. Disponível em: <http://www.apliquimbrasilrecicle.com.br> Acesso em: 22 mar. 2016.

\section{ASSOCIAÇÃO BRASILEIRA DE EMPRESAS DE LIMPEZA PÚBLICA E RESÍDUOS ESPECIAIS. Panorama dos resíduos sólidos no Brasil. São Paulo, 2016 (ABRELPE, 2016).}

ASSOCIAÇÃO BRASILEIRA DE NORMAS TÉCNICAS. NBR 10004: resíduos sólidos: classificação. Rio de Janeiro, ABNT, 2004.

BRASIL. DECRETO N 7.404, de 23 de dezembro de 2010. Regulamenta a Lei $n^{\circ} 12.305$ de agosto de 2010, que institui a Política Nacional de Resíduos Sólidos. Diário Oficial da União, Brasília, 23 dez. 2010 (BRASIL, 2010b).

BRASIL. LEI N¹2.305, de 02 de agosto de 2010. Institui a Política Nacional de Resíduos Sólidos; altera a Lei no 9.605, de 12 de fevereiro de 1998; e dá outras providências. Diário Oficial União, Brasília, 2 ago. 2010.

(BRASIL, 2010c).

DEMAJOROVIC J.; LIMA M. Cadeia da reciclagem: um olhar para o catador. São Paulo: Senac, 2013, p. 83.

DURÃO JUNIOR, W.A.; WINDMÖLLER, C.C. Química nova escola: a questão do mercúrio em lâmpadas fluorescentes. São Paulo: Abril, v. 28, maio, 2008. Mensal.

ENVIRONMENT PROTECTION AGENCY. Control Technology Center. Evaluation of mercury emission from fluorescent lamp crushing. Durham: Office of air quality planning and standards, 1994. 20p.

JACOBI, P. R.; BESEN, G. R. Gestão de resíduos sólidos em São Paulo: desafios da sustentabilidade. Estudos Avançados, São Paulo, v. 25, n. 71,p. 135-158, jan. / apr. 2011.

KARPINSK, L. A. et al. Gestão diferenciada de resíduos de construção civil: uma abordagem ambiental. Porto Alegre: Edipucrs, 2009. Cap. 1. p. 10-163.

MINISTÉRIO DO MEIO AMBIENTE. Relatório de Desempenho de Sistema de Logística Reversa, 2017. Disponível em: http://mma.gov.br/images/arquivo/Relatorio_MMA_final_atividades_2.016_2_versao_.pdf Acesso em: 14 abr. 2018. (MMA, 2017)

MISSIAGGIA, M. Dez formas de reduzir o consumo de energia elétrica. Diário do Comércio, São Paulo, fev. 2015. Disponível em: <http://www.abilux.com.br/portal/abilux-na-midia/2/10-formas-de-reduzir-o-consumo-de-energiaeletrica> Acesso em 30 jun. 1998.

MORESI, E.(Org.). Metodologia de pesquisa. Brasília, 2003. 108p.

POLANCO, S.L.C. A situação da destinação pós-consumo de lâmpadas de mercúrio no Brasil. 2007. 119 p. Dissertação (mestrado) - Programa de Pós-Graduação Engenharia de Processos Químicos e Bioquímicos, Centro Universitário do Instituto Mauá de Tecnologia, São Caetano do Sul, 2007.

PROCEL INFO, 2006. Selo Procel Edificações. Disponível em:

<http://www.procelinfo.com.br/main.asp?View=\{8E03DCDE-FAE6-470C-90CB-922E4DD0542C\}>Acesso em: $10 \mathrm{abr}$. 2017

RECICLUS, 2016. Consulta geral a homepage. Disponível em:

< http://www.reciclus.org.br/index.php?content=11> . Acesso: 07 set. 2016.

.E-mail pessoal enviado por sustentabilidade@reciclus.org.br em 25 abr. 2018.

ROCHA, M. Escritório de consultoria e comunicação. São Paulo, 23 ago. 2016. Entrevista concedida a Samara Nicolau Puopolo. 


\section{Revista Nacional de}

Gerenciamento de Cidades

National Journal of Cities Mamagement

SÃO PAULO (Estado). Resíduo sólido: Cadernos de Educação Ambiental. 2. ed. São Paulo: Secretaria do Meio Ambiente, 2014. 164 p. (SÃO PAULO, 2014a)

SÃO PAULO (Município). Comitê Intersecretarial para a Política Municipal de Resíduos Sólidos. Plano de gestão integrada de resíduos sólidos da cidade de São Paulo. São Paulo, 2014, 456 p. (SÃO PAULO, 2014b)

SISTEMA NACIONAL DE INFORMAÇÃO SOBRE A GESTÃO DE RESÍDUOS SÓLIDOS, 2017. Acordo Setorial de Lâmpadas Fluorescentes de Vapor de Sódio e Mercúrio e de Luz Mista. Disponível em :

$<$ http://www.sinir.gov.br/web/guest/acordo-setorial-de-lampadas-fluorescentes-de-vapor-de-sodio-e-mercurio-ede-luz-mista > Acesso em 20 mar. 2017 (SINIR, 2017).

TRAMPPO, 2016. Consulta geral a homepage oficial. Disponível em: < http://www.tramppo.com.br/> Acesso em : 08 mar. 2016.

.E-mail pessoal enviado por Tramppo@iglobal.net.br em 21 mai. 2018.

UNITED NATIONS ENVIRONMENT PROGRAMME. Mercury: Acting Now! Geneva: UNEP, 2013. 24 p.

WIENS, C. H. Resíduos Sólidos: o caso das lâmpadas fluorescentes descartadas em quatro empresas do setor automobilístico da Região Metropolitana de Curitiba. Porto Alegre: UFRGS, 2001. 